\title{
Author Index for Volume 24
}

Abdollahi, M.

Ahmadi Amoli, K.

Ai, C.R.

Arkian, S.Sh.

Bai, P.F.

Bai, R.P.

Basnet, D.K.

Bhattacharyya, J.

Bian, Z.H.

Cao, T.Y.

Chen, G.Y.

Chen, H.X.

Chen, Y.Q.

Dar, N.A.

Darafsheh, M.R.

Fa, H.X.

Feng, R.Q.

Feng, Z.C.

Gao, H.W.

Guo, L.

Guo, S.T.

Guo, W.B.

Guo, X.Y.

Haghighi, H.

Han, J.Z.

He, Z.H.

Hou, H.L.

$\mathrm{Hu}, \mathrm{S} . \mathrm{N}$.

Huang, Q.X.
467

509

315,407

551

685

519

481

481

297

577

153,323

673

323,647

393

467

697

381

123, 181

351

53

453

75,255

685

401

697

169

453

705

541
Huang, X.Y.

541

Kang, C.C.

519

Keskin Tütüncü, D.

603

Khan, A.N.

393

Kolesnikov, P.S.

563

Koshitani, S.

439

La Barbiera, M.

83

Li, C.H.

123,181

Li, J.B.

Li, Y.

153,697

267

351

Li, Z.X.

123,181

Li, Z.Y.

519

407

297

75

541

509

Mafi, A.

625

Mahmoudi, M.

625

Mehdi Ebrahimi, M.

361

Mitsch, H.

267, 493

Mo, Q.H.

439

Müller, J.

673

Nan, J.Z.

233

Nikseresht, A.

611

Obul, A.

109

Pan, Q.N.

493

Prajapati, S.K. 
Preusser, R.

195

Ruan, W.L.

Sarma, R.

Skiba, A.N.

75,255

Staglianò, P.L.

Sun, J.C.

285

Sun, X.T.

Tabejamaat, S.

509

Tang, X.

Tribak, R.

603

Wang, Q.W.

169,233

Wang, Y.

673

$\mathrm{Xu}, \mathrm{Y}$.

453

Yang, X.Y.

577

Yassemi, S.

401

Yavari, M.

625

Yunus, G.

109

Zaare-Nahandi, R.

401,611

Zeng, L.W.

381

Zeng, Y.

153

Zhang, B.R.

685

Zhang, G.L.

323

Zhang, H.L.

285

Zhang, P.

639

Zhang, Y.

233, 381, 519

Zhang, Z.R.

647

Zhao, J.Y.

705

Zhao, X.G.

309, 493

Zhou, S.Y.

53

Zhu, L.

639 